\title{
Effect of ATP and Bax on the apoptosis of Eimeria tenella host cells
}

\author{
Zhiyong Xu ${ }^{1,2}$, Mingxue Zheng ${ }^{1 *}$, Li Zhang ${ }^{1}$, Xuesong Zhang ${ }^{1}$, Yan Zhang ${ }^{1}$, Xiaozhen Cui ${ }^{1}$, Xin Gong ${ }^{1}$, Rou Xi ${ }^{1}$ \\ and Rui Bai ${ }^{1}$
}

\begin{abstract}
Background: Eimeria tenella (E. tenella) is a species of Eimeria that causes haemorrhagic caecal coccidiosis, resulting in major economic losses in the global poultry industry. After E. tenella infection, the amount of ATP and Bax in host cells showed highly significant changes. Therefore, it is necessary to investigate the effects of ATP and Bax on the apoptosis of E. tenella host cells.

Results: The ATP-treated group and the V5-treated group had higher E. tenella infection rates than the untreated group at 24, 48, 72, 96, and $120 \mathrm{~h}$ after infection with E. tenella. The results of flow cytometry showed that compared with the control group, the mitochondrial permeability transition pore (MPTP) opening in the untreated group was highly significantly increased $(P<0.01)$ at 4, 24, 48, 72, 96, and $120 \mathrm{~h}$. Moreover, results from Hoechst-Annexin V-PI staining and flow cytometry showed that the rates of early apoptosis, late apoptosis, and necrosis in the untreated group were significantly lower $(P<0.05)$ or highly significantly lower $(P<0.01)$ than those of the control group at $4 \mathrm{~h}$, while the rates of early apoptosis, late apoptosis, and necrosis in the untreated group were higher at varying degrees than those in the control group at 24-120 h $(P<0.05$ or $P<0.01)$. After treatment with ATP and Bax inhibitors, the rates of early apoptosis, late apoptosis, and necrosis, in addition to the MPTP opening in both the ATP-treated and V5-treated groups, were significantly lower $(P<0.05)$ or highly significantly lower $(P<0.01)$ than those in the untreated group.
\end{abstract}

Conclusions: ATP and Bax play important roles in regulating the apoptosis of E. tenella host cells.

Keywords: Eimeria tenella, Host cell, Apoptosis, ATP, Bax

\section{Background}

Eimeria tenella (E. tenella) is the most common species of Eimeria, and it parasitises chicken intestinal mucosa epithelial cells. After infection with E. tenella, the mortality rates in chickens increase up to $80 \%$, whereas weight and egg production significantly decrease [1, 2]. These conditions result in major economic losses in the global poultry industry $[3,4]$.

E. tenella primarily damages the chicken caecum. The apoptosis rate of duodenal mucosal cells infected with Eimeria acervulina reaches the highest at 0.5 and 5 days [5]. E. tenella-infected embryo caecal epithelial cells have shown decreased apoptosis at early developmental stages (24 $\mathrm{h}$ or less) but have conversely shown increased

\footnotetext{
* Correspondence: zhengmingxue288@163.com

${ }^{1}$ College of Animal Science and Technology, Shanxi Agricultural University,

Taigu 030801, China

Full list of author information is available at the end of the article
}

apoptosis at the middle and late developmental stages $(24-120 \mathrm{~h})$ [6]. The degree to which the mitochondrial membrane KATP channel opens has been shown to decrease the apoptosis rate of cells infected with E. tenella and promote the development of E. tenella in chicken caecum epithelial cells [7]. The mitochondrial apoptotic pathway is regulated by concentration changes in $\mathrm{Ca}^{2+}$ outside of $E$. tenella host cells and endoplasmic reticulum $\mathrm{Ca}^{2+}$ channels [8]. The amount of apoptosis in intestinal epithelial cells infected with E. tenella is consistent with the severity of injury to the mitochondrial structure. These observations indicate a positive correlation of apoptosis in cells infected with $E$. tenella with changes in mitochondrial structure [9].

The mitochondrial permeability transition pore (MPTP), a compound channel composed of multiple proteins, is located between inner and outer mitochondrial membranes. A previous study showed that MPTP is a key node that 
plays a predominant role in the mitochondrial apoptosis pathway in host cells induced by E. tenella [10]. Cyclophilin D has previously been identified as an essential component of the MPTP structure [11]. Other studies have also suggested that MPTP potentially comprises a voltage-dependent anion channel (VDAC) and an adenine nucleotide transporter (ANT) [12]. Adenosine triphosphate (ATP) is the sole supplier of energy in living organisms. To maintain cell metabolic activity, ATP is transported into the cytoplasm via ANT, whereas cytoplasmic ADP is transported to mitochondria via ANT, which provides the raw material for oxidative phosphorylation [13]. During ischaemia and hypoxia, decreased levels of ATP result in increased concentrations of cytoplasmic phosphorus and calcium ions and the production of a large number of superoxides, thus further promoting MPTP opening and eventually leading to cell death [14]. Bcl-2 family proteins can be divided into two categories as follows: proapoptotic proteins, such as Bax, Bak, Bad and Bid, and anti-apoptotic proteins, such as $\mathrm{Bcl}-2$ and $\mathrm{Bcl}-\mathrm{xl}$. Bax primarily resides in the cytoplasm. Apoptosis stimuli increase $\mathrm{BH} 3$ expression, which enhances the effects of $\mathrm{Bax}$ and Bak by combining with Bcl-2 and Bcl-xl, further promoting cell apoptosis [15]. A previous study demonstrated that Bax could promote cell apoptosis by combining with VDAC [16].

The caspase-9 inhibitor Z-LEHD-FMK can significantly increase the infection rate of $E$. tenella by inhibiting host cell apoptosis [6]. In animal models, the inhibition of MPTP by either cyclosporin A (CsA) or the genetic ablation of CyP-D provides strong protection from both reperfusion injury and congestive heart failure [17]. Other evidence also suggests that apoptosis can be reversed by anti-apoptotic drugs, which can rescue cells and provide new directions for the protective treatment of an organism by avoiding or controlling harmful processes [18]. The control of host-cell apoptosis had been demonstrated as complementary in the treatment of parasitic diseases [19].

In a recent study, we showed that the Bax amount in E. tenella host cells visibly decreased during the early developmental stages of E. tenella and, conversely, remarkably increased during the middle and later developmental stages [20]. The ATP content decreased at all developmental stages of E. tenella [20]. In the present study, we further investigated the effects of ATP and Bax on the apoptosis of $E$. tenella host cells in vitro by flow cytometry (FC), Hoechst-fluorescein isothiocyanateconjugated Annexin V-propidium iodide (HoechstAnnexin V-FITC-PI) staining and primary chick embryo caecum epithelial cell culture techniques. These results can provide a theoretical foundation for studying the mechanism of E. tenella-induced apoptosis in host cells and exploring anti-apoptotic adjuvant treatment of $E$. tenella infection in chickens.

\section{Methods \\ Experimental animals}

A total of twenty 1-day-old chicks and one hundred 15day-old specific pathogen-free (SPF) chicken embryos were used in the present study and were provided by Beijing Meri Avigon Laboratory Animal Technology Co., Ltd. (Beijing, China). The 1-day-old chicks were raised under strict pathogen-free conditions (Isolator. Temperature and pressure: $1-3 \mathrm{~d}, 35-36{ }^{\circ} \mathrm{C}, 25 \mathrm{~Pa} ; 4-7$ d, 32-35 ${ }^{\circ} \mathrm{C}, 25-35 \mathrm{~Pa} ; 8-14 \mathrm{~d}$ : $29-32{ }^{\circ} \mathrm{C}, 35-45 \mathrm{~Pa}$; $15-21 \mathrm{~d}, 21-25{ }^{\circ} \mathrm{C}, 55-75 \mathrm{~Pa} ; 22-30 \mathrm{~d}, 21-25{ }^{\circ} \mathrm{C}$, and 55-75 Pa. Humidity: 1-10 d, 65-70\%; 11-30 d, 60-65\%).

\section{Parasites}

The E. tenella Shanxi virulent strain (EtSX01) used in the present study was obtained from the Laboratory of Veterinary Pathology in the College of Animal Science and Technology (Laboratory of Veterinary Pathology, Shanxi Agricultural University; Taigu, China).

\section{Preparation of $E$. tenella Sporozoites}

E. tenella was amplified by passage through twenty 20 day-old SPF chicks previously infected orally with 6000 sporulated $E$. tenella oocysts. The resulting oocysts were obtained from the faeces of chickens at seven to eight days post-infection. After the oocysts were isolated and sporulated, the sporozoites were excysted as previously described [6]. The chicks were euthanized with cervical dislocation under deep Nembutal anaesthesia $[45 \mu \mathrm{g} / \mathrm{g}$ of body weight (BW), intraperitoneal injection; Shanghai Chemical Factory, Shanghai, China].

\section{Primary culture of Chick embryo Caecal cells and parasite infection}

One hundred 15-day-old SPF chick embryos (Merial Vital Corp, Beijing, China) were euthanized with cervical dislocation under deep Nembutal anaesthesia $(45 \mu \mathrm{g} / \mathrm{g}$ of BW) for sample preparation. Chick embryo caecal epithelial cells were collected and cultured as previously described [7]. The caeca were briefly removed and placed in PBS, minced to $1 \mathrm{~mm}^{3}$, digested by $50 \mathrm{mg} / \mathrm{l}$ thermolysin (Sigma, California, America) at $37{ }^{\circ} \mathrm{C}$ for $2 \mathrm{~h}$, rinsed with PBS, and centrifuged at $220 \mathrm{~g}$ for $5 \mathrm{~min}$ to remove single cells. Prior to plating, based on the adherence speed of each cell, the precipitated dissociated cells were cultivated for $70 \mathrm{~min}$ at $41{ }^{\circ} \mathrm{C}$ in a humidified, $8 \% \mathrm{CO}_{2}$-air incubator to remove all other cells, except the caecal epithelial cells in culture medium (DMEM; Sigma, California, America) supplemented with 10\% FBS [6]. Non-adherent caecal epithelial cell aggregates were maintained at $41{ }^{\circ} \mathrm{C}$ in a humidified incubator with $8 \%$ 
$\mathrm{CO}_{2}$. The cells were subsequently plated at a concentration of $2 \times 10^{5}$ live cell aggregates per well onto a 6-well tissue culture plate in culture medium supplemented with 2.5\% FBS [6]. Confluent chick embryo caecal epithelial cell monolayers were infected with $4 \times 10^{5}$ freshly excysted E. tenella sporozoites per well.

\section{Experimental protocol}

When the adherence rate reached $90 \%$, chick embryo caecal epithelial cells in 6-well tissue culture plates were randomly divided into four experimental groups, as follows: (1) the control group (group C); (2) the untreated group (cells infected with $E$. tenella sporozoites, group T0); (3) the treated group I [cells infected with E. tenella sporozoites and treated with $30 \mu \mathrm{mol}$ of ATP (Sigma, California, America), group T1]; and (4) the treated group II [cells infected with E. tenella sporozoites and treated with $150 \mu \mathrm{mol}$ of V5 (H-VPMLK-OH, BaxInhibiting Peptide; Merck, New Jersey, America), group T2]. The cells were collected at 4, 24, 48, 72, 96, and $120 \mathrm{~h}$ after infection. In addition, the culture liquid was changed every $48 \mathrm{~h}$. Cells in group T1 that were sampled at 4-24 h were treated with ATP at the time of infection with $E$. tenella sporozoites, whereas the cells sampled at 48-120 h were treated with ATP $24 \mathrm{~h}$ prior to sampling. Cells in group T2 that were sampled at $4 \mathrm{~h}$ were treated with V5 at the time of infection with E. tenella sporozoites, while the cells sampled at $24-120 \mathrm{~h}$ were treated with V5 $4 \mathrm{~h}$ prior to sampling.

\section{Haematoxylin and eosin stain (HE staining)}

At 4, 24, 48, 72, 96, and $120 \mathrm{~h}$ after infection, the chamber slides of groups $\mathrm{C}$ and $\mathrm{T} 0$ were collected and subsequently stained with Lillie-Mayer's haematoxylin (Solarbio) and $1 \%$ eosin (Solarbio) as previously described [6]. Sample $E$. tenella infections were observed in 200 randomly selected cells by light microscopy.

The infection rates at each time point $(\%)=$ the number of infected cells at each time point $/ 200 \times 100$.

\section{Dynamic detection of MPTP opening in E. tenella host cells}

Fluorescent Calcein AM (Life Technology, New York, America; Cat.C3099 Lot: 1,311,548) and $\mathrm{CoCl}_{2}$ (Sigma, Lot: 232,696 No: BCBG0246V) markers were employed to detect the dynamic changes of MPTP opening using FC. At 4, 24, 48, 72, 96, and $120 \mathrm{~h}$ after infection, chick embryo caecal epithelial cells were harvested using $0.25 \%$ trypsin, rinsed in PBS, centrifuged at $600 \mathrm{~g}$ for $5 \mathrm{~min}$, suspended in $200 \mu \mathrm{l}$ of binding buffer (Sigma, California, America), and incubated with Calcein AM and $\mathrm{CoCl}_{2}\left(15 \mathrm{~min}, 37{ }^{\circ} \mathrm{C}\right.$, in the dark). Subsequently, $250 \mu \mathrm{l}$ of binding buffer was added to the cells, and the mixture was subjected to FC analysis. Flow cytometry
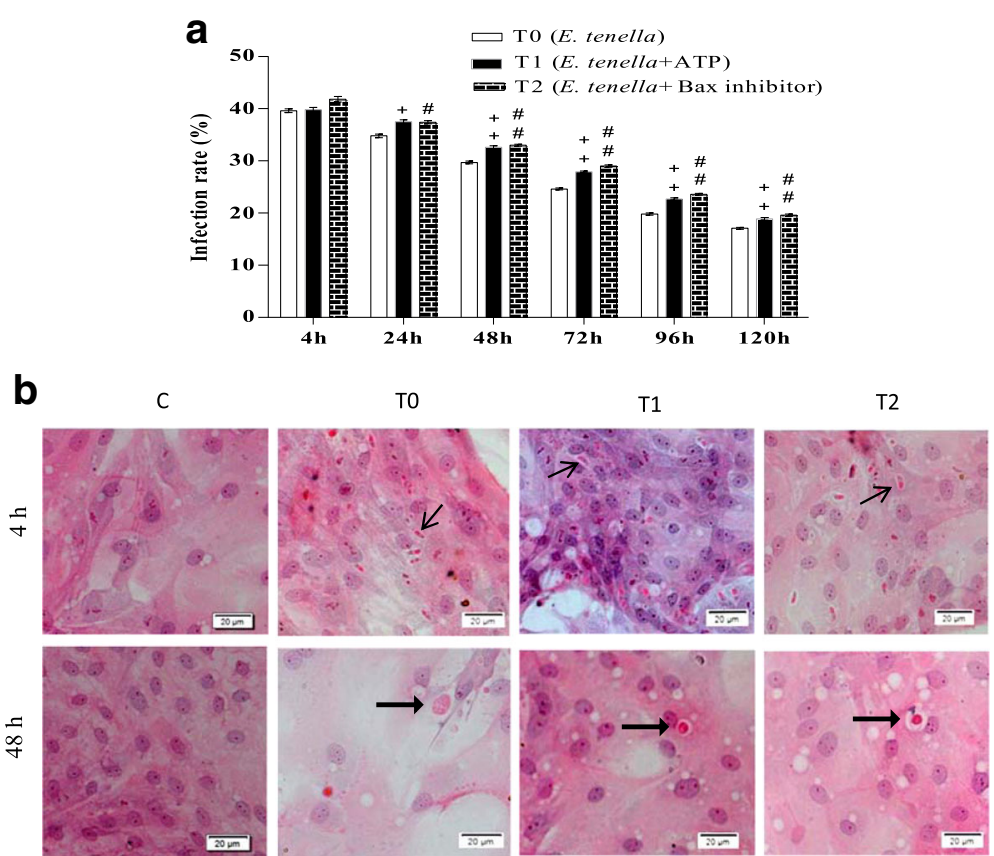

Fig. 1 E. tenella infection rates. a Quantitative determination of E. tenella infection $(n=5)$. b Caecal epithelial cells in groups $C$, T0, T1, and T2 at 4, and $48 \mathrm{~h}$, respectively. ${ }^{+} P<0.05$ vs. T0, ${ }^{++} P<0.01$ vs. T0; ${ }^{\#} P<0.05$ vs. T0, ${ }^{\# \#} P<0.01$ vs. T0, as indicated below the figures. " $\rightarrow$ " represents sporozoites, " $\rightarrow$ " represents trophozoites. Magnification 400x 
(American BD, FACSCalibur) was performed as previously described [21]. The results were analysed using CellQuest software. Fluorescent intensity reflects a change in MPTP opening [22].

\section{Dynamic detection of apoptosis in E. tenella host cells}

The Annexin V-FITC/PI (Invitrogen, New York, America; Lot: 1,223,786, model: V13241) was used in the present study. The methods used to harvest and incubate the cells were consistent with those used to detect MPTP opening. Subsequently, chick embryo caecal epithelial cells were re-suspended and incubated with $5 \mu \mathrm{l}$ of Annexin V-FITC and $1 \mu \mathrm{l}$ of PI for $30 \mathrm{~min}$ at room temperature in the dark. Next, the cells were added to $200 \mu \mathrm{l}$ of binding buffer and subjected to FC analysis. Annexin V-/PI- quadrant: viable cells; Annexin V+/PIquadrant: early apoptotic cells; Annexin $\mathrm{V}+/ \mathrm{PI}+$ quadrant: late apoptotic and necrotic cells.

Annexin V-FITC/PI and Hoechst 33,342 (Beyotime, Shanghai, China; cat: C1025) markers were employed to detect the apoptosis rate under a fluorescence microscope (OLYMPUS, Japan). The procedures were performed according to Venkatanarayan [23]. Briefly, at 4, 24, 48, 72, 96, and $120 \mathrm{~h}$ after infection, the culture media from groups $\mathrm{C}$ and $\mathrm{T} 0$ were aspirated into suitable centrifuge tubes. Subsequently, chick embryo caecal epithelial cells were harvested using $0.25 \%$ trypsin, centrifuged at $1000 \mathrm{~g}$ for $5 \mathrm{~min}$, and suspended with $1 \mathrm{ml}$ of ice-cold PBS. The cells were centrifuged at $1000 \mathrm{~g}$ for 5 min and gently suspended in $400 \mu \mathrm{l}$ of $1 \times$ binding buffer $\left(1 \times 10^{5}\right.$ cell density), to which $5 \mu \mathrm{l}$ of $2 \mu \mathrm{g} / \mathrm{ml}$ Hoechst 33,342 was added at $37{ }^{\circ} \mathrm{C}$. The mixture was allowed to stand for $15 \mathrm{~min}$, centrifuged at $1000 \mathrm{~g}$ for $5 \mathrm{~min}$, and gently suspended in $400 \mu \mathrm{l}$ of $1 \times$ binding buffer. Subsequently, $5 \mu \mathrm{l}$ of Annexin V-FITC was added in the dark at room temperature. After $15 \mathrm{~min}, 10 \mu \mathrm{l}$ of $100 \mu \mathrm{g} / \mathrm{ml}$ PI was added in the dark on ice; after $5 \mathrm{~min}$, the resulting mixture was again centrifuged at $1000 \mathrm{~g}$ for $5 \mathrm{~min}$. The cells were suspended in $50 \mu \mathrm{l}$ of $1 \times$ binding buffer. Images were captured using a fluorescence microscope and CellSens software. Apoptotic cells were observed in 200 randomly selected sample cells and 5 parallel samples at each time point. The cells were distinguished as normal cells (Hoechst 33,342+/Annexin V+), early apoptosis cells (Hoechst33342+/Annexin $\mathrm{V}++$ ), and late apoptosis and necrosis cells (Annexin $\mathrm{V}++/ \mathrm{PI}++$ ).

\section{Statistical analysis}

All quantitative data were analysed by ANOVA in SPSS 19.0 (SPSS Inc., Chicago, Illinois, USA) and expressed as the means \pm SE. A $p$-value of $<0.05$ was considered significant.

\section{Results}

ATP and Bax-inhibitor increased $E$. tenella infection rates The E. tenella infection rate was detected by $\mathrm{HE}$ staining (Fig. 1a-b; Additional file 1). The results indicated that although no significant difference in $E$. tenella infection rates was observed among T0, T1 and $\mathrm{T} 2$ groups at $4 \mathrm{~h}$ after infection by $4 \times 10^{5} \mathrm{E}$. tenella sporozoites per chamber slide $(P>0.05)$, and groups T1 and T2 exhibited higher $E$. tenella infection rates than group T0 $(P<0.05$ or $P<0.01)$ at 24 , $48,72,96$ and $120 \mathrm{~h}$ after infection.

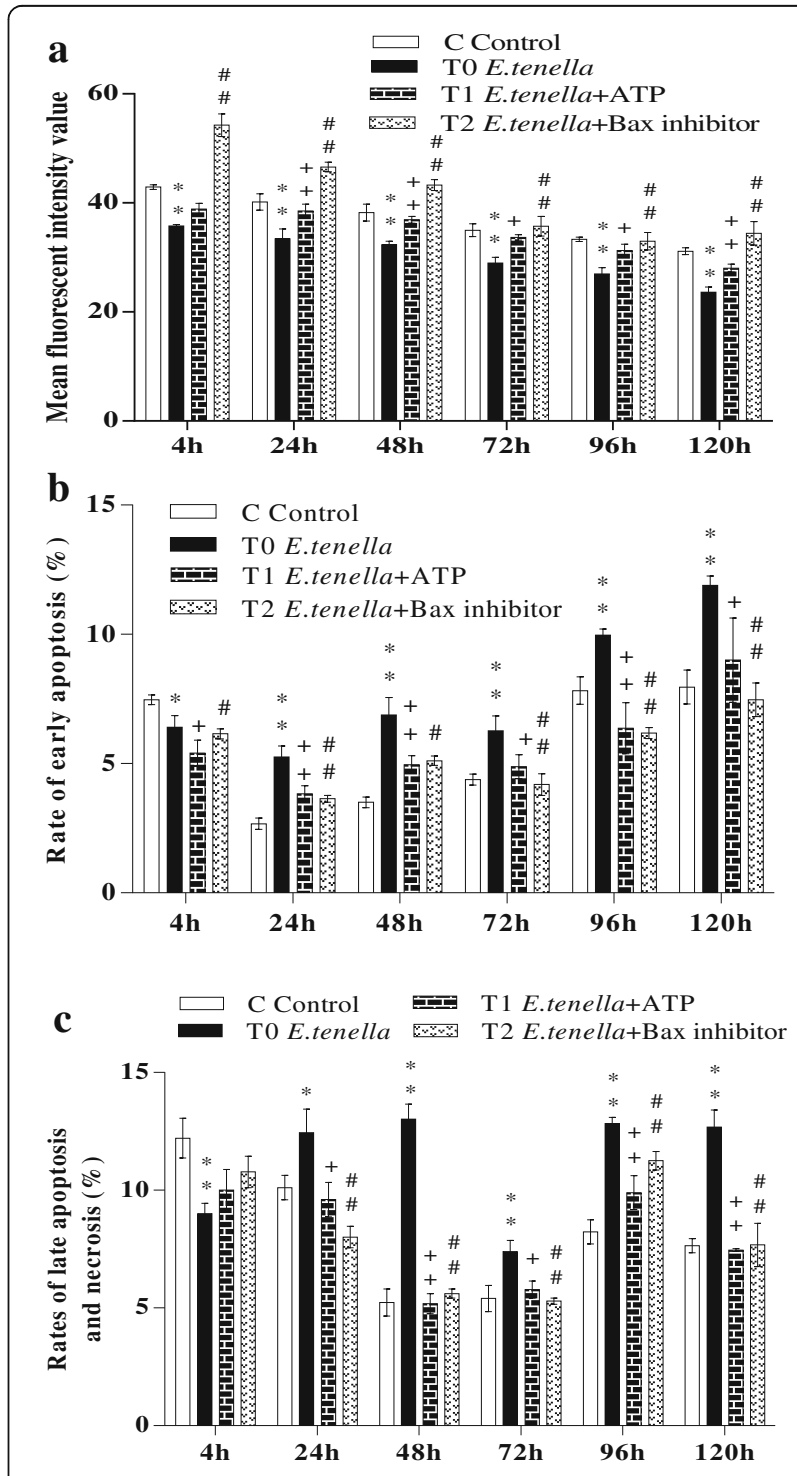

Fig. $\mathbf{2}$ The influence of ATP and Bax on MPTP opening and the rate of early apoptosis, late apoptosis, and necrosis of E. tenella host cells. $\mathbf{a}$ Effect of ATP and Bax on MPTP opening of E. tenella host cells. $\mathbf{b}$ Effect of ATP, and Bax on the early apoptosis rate of E. tenella host cells. c Effect of ATP and Bax on the rate of late apoptosis, and necrosis of $E$. tenella host cells. ${ }^{*} P<0.05$ vs. $C,{ }^{* *} P<0.01$ vs. $C$, the same as below figures 


\section{ATP and Bax-inhibitor decreased MPTP opening in E. tenella host cells}

A higher fluorescence value indicates a lower degree of MPTP opening. MPTP opening of the cells in groups $\mathrm{C}, \mathrm{T} 0, \mathrm{~T} 1$ and $\mathrm{T} 2$ were detected by FC. The results showed that MPTP opening of group T0 was higher $(P$ $<0.01$ ) than that of group $C$ at 4, 24, 48, 72, 96, and $120 \mathrm{~h}$ (Figs. 2a and 3; Additional file 2). The results also indicated that MPTP opening of group T1 was visibly lower $(P<0.05$ or $P<0.01)$ than that of group T0 (Figs. 2a and 3). MPTP opening of group T2 was also lower $(P<0.01)$ than that of group T0 (Figs. 2a and 3; Additional file 2).

\section{ATP and Bax-inhibitor decreased apoptosis rate of $E$. tenella host cells}

Early apoptosis, late apoptosis and necrosis rates in groups $\mathrm{C}, \mathrm{T} 0, \mathrm{~T} 1$ and $\mathrm{T} 2$ were detected by $\mathrm{FC}$ and Hoechst-Annexin V-FITC-PI staining. The results of FC showed that $4 \mathrm{~h}$ after infection with E. tenella, the early apoptosis, late apoptosis and necrosis rates in group T0 were lower than those in group C, whereas the early apoptosis, late apoptosis and necrosis rates in group $\mathrm{T} 0$ were higher than those in group $\mathrm{C}$ to varying degrees at 24, 48, 72, 96 and $120 \mathrm{~h}$ (Figs. 2b-c, and 4; Additional files 3 and 4). The results of Hoechst-Annexin V-FITC-PI staining showed that the early apoptosis rate in group T0 significantly decreased at $4 \mathrm{~h}(P<0.01)$ compared with that in group $C$. However, the early apoptosis rate in group T0 significantly increased at 24, 48, 72, 96 and $120 \mathrm{~h}(P<0.05$ or $P<0.01)$ compared with that in group $C$ (Fig. 5a and c; Additional file 5). Compared with rates of late apoptosis and necrosis in group $\mathrm{C}$, those in group T0 significantly decreased at $4 \mathrm{~h}(P<$ $0.05)$ and did not significantly differ at $24 \mathrm{~h}(P>0.05)$ but highly significantly increased at 48, 72, 96 and $120 \mathrm{~h}(P<0.05$ or $P<0.01)$ (Fig. 5b and c; Additional file 6). Group T1 showed significantly lower or highly significant rates of early apoptosis, late apoptosis and necrosis than group T0 (Figs. 2b-c, 4, and 5a-c; Additional files 5 and 6). The rates of early apoptosis, late apoptosis and necrosis in group T2 were significantly lower or highly significantly lower compared to those in group T0 (Figs. 2b-c, and 4, and 5a-c; Additional files 5 and 6).

\section{Discussion}

As an intracellular parasite, the infection rate of $E$. tenella was the basic condition of this experiment. The results showed that group T0 host cells featured high rates of E. tenella infection (Fig. 1a-b; Additional file 1),

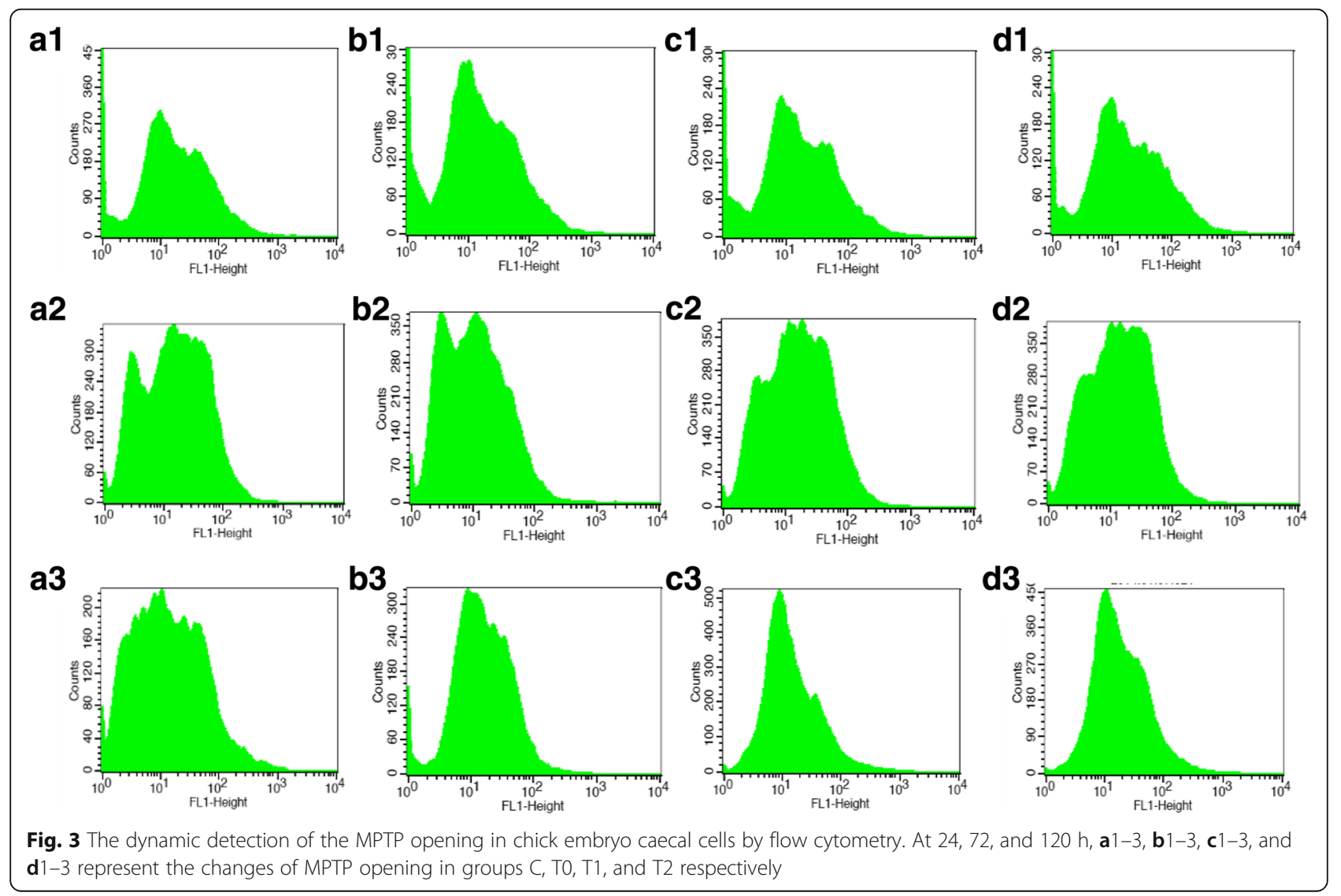



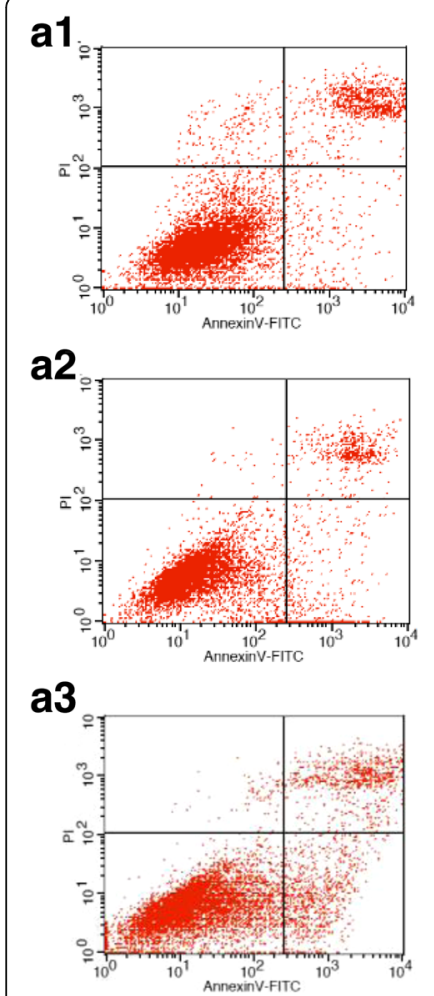

b1

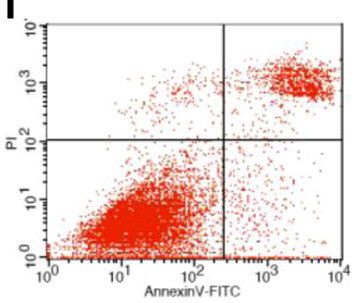

b2

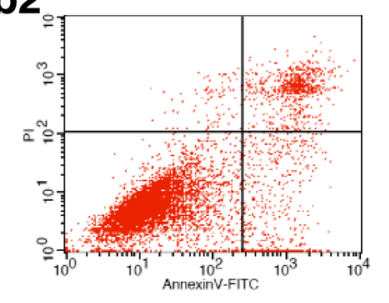

b3

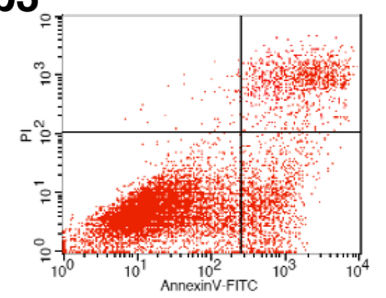

c1

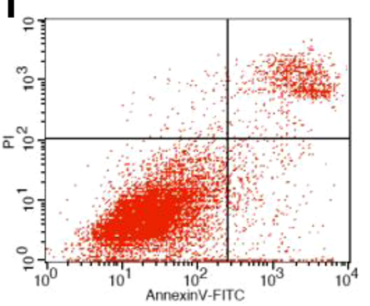

c2

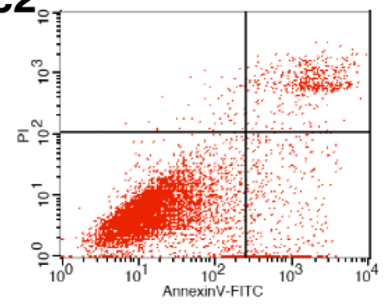

c3

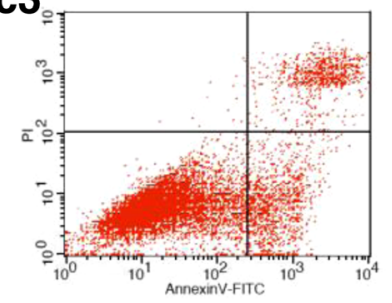

d1

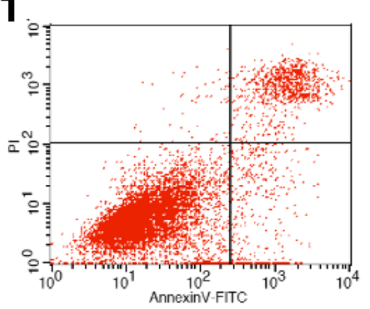

d2

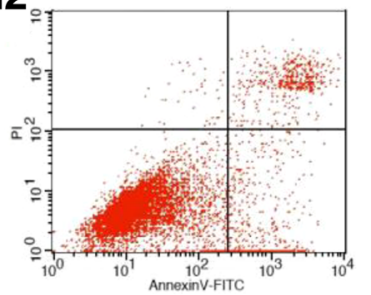

d3

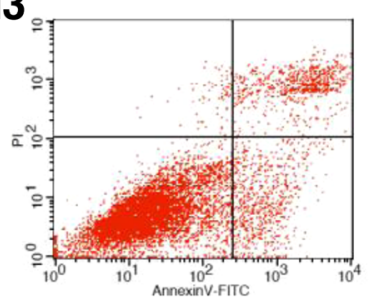

Fig. 4 Annexin V/PI-based apoptosis detection in chick embryo caecal cells by flow cytometry. At 24, 72, and 120 h, a 1-3, b1-3, c1-3, and d $1-3$ represent the rates of early apoptosis, late apoptosis and necrosis of groups C, T0, T1, and T2 respectively

and the infection rates decreased with prolonged infection time, consistent with the results obtained in previous reports [6]. After treatment with ATP and Bax inhibitor, E. tenella infection rates remarkably increased, indicating the successful construction of experimental models.

After infection with E. tenella, the results of the two methods were consistent and showed that E. tenella inhibited host cell apoptosis during the early stages of $E$. tenella development and promoted host cell apoptosis during the middle and late developmental stages, supporting previous results $[6,24]$. E. tenella also increased host-cell MPTP opening.

ATP plays a key role in maintaining normal cellular functions. The results by FC showed that ATP inhibited MPTP opening. The results of the two other methods used were consistent in this experiment, showing that ATP decreased the host cell apoptosis rate. ATP synthesis mainly depends on the mitochondrial membrane potential, and antioxidants can inhibit cell apoptosis by preventing decreases in ATP [25]. The exchange between ATP in mitochondria and ADP in the cytoplasm occurs via ANT. High concentrations of ATP can stabilise ANT in M constellation to inhibit MPTP opening, thus further preventing cell apoptosis [26]. Upon serious stimulation, MPTP of the cell irreversibly opens, uncoupling oxidative phosphorylation, inhibiting ATP synthesis, and promoting ATP decomposition, eventually leading to necrocytosis [27]. A decrease in ATP results from the exhaustion of the membrane potential gradient caused by MPTP opening, and the release of apoptosis factors occurs due to swelling and the fracture of mitochondria caused by MPTP opening [28, 29]. In the present study, after treatment with ATP, MPTP opening in host cells was significantly inhibited, and the apoptosis rate of host cells significantly decreased, showing that ATP is a key factor in regulating the apoptosis of $E$. tenella host cells. These results are consistent with those of previous studies $[25,26]$. At $4 \mathrm{~h}$ after infection with E. tenella, MPTP opening was increased in group T0 cells, whereas the apoptosis rate in group T0 decreased (Fig. 2a-c; Additional file 2). This result was due to a notable increase in the amounts of nuclear factor- $\mathrm{k} B$ and Bcl-xl, which can inhibit host cell apoptosis during the early stages of E. tenella development [30]. The involvement of other factors in this process must be further studied.

Bax is an important pro-apoptotic protein in the Bcl-2 family. V5 is a Bax-inhibitor and can protect cells from Bax-mediated apoptosis. The results of FC showed that 


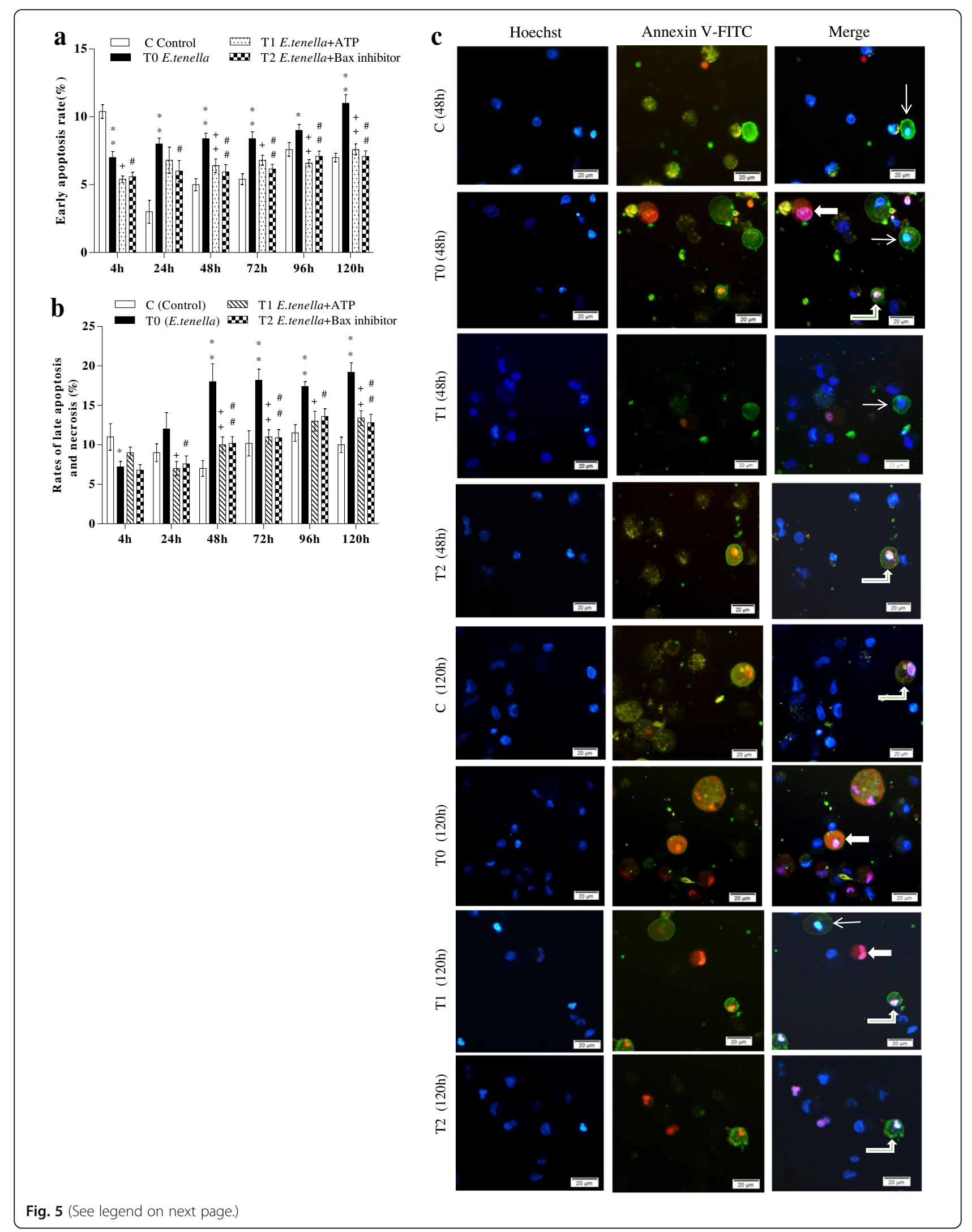


(See figure on previous page.)

Fig. 5 Hoechst-Annexin V/PI-based apoptosis detection in chick embryo caecal cells. a Quantitative determination of early apoptosis ( $n=5)$. b Quantitative determination of late apoptosis and necrosis $(n=5)$. c Hoechst staining (blue) and Annexin V/PI staining (green/red) to detect apoptosis cells in group C, T0, T1 and T2 at 48 and 120 h, respectively; merge is Hoechst staining/Annexin V/Pl staining overlay. " $\longrightarrow$ " represents early apoptosis cell, " $\mathbf{\boldsymbol { \Lambda }}$ " represents late apoptosis cell, " $\vec{\longrightarrow}$ " represents necrosis cell. Magnification 400

the Bax inhibitor inhibited MPTP opening. The results of the other two methods used were consistent in this experiment, showing that the Bax inhibitor decreased the host cell apoptosis rate. Bax may regulate the mechanism of cell apoptosis in the following manner: first, Bax mediates changes in mitochondria permeability, further causing the synthetic obstruction of ATP; subsequently, Bax changes cell oxidation-reduction; third, Bax releases relevant factors that activate the signalling pathways of the caspase family [31]. Bax is assumed to regulate mitochondrial membrane permeability in two ways: first, Bax directly regulates MPTP opening [32]; second, Bax forms pores in the mitochondrial membrane and regulates mitochondrial membrane permeability. Brenner reported that Bax can combine with ANT and form pores in an artificial lipid bilayer in vitro, although the combination of Bcl-2 and ANT can inhibit the formation of Bax channels, thus further inhibiting changes in mitochondrial membrane permeability [33]. Studies have demonstrated that the oligomerisation of Bax subfamily proteins is promoted by the interactions of $\mathrm{BH}-3$ and Bax subfamily proteins, and these complexes enter mitochondria to release cytochrome $\mathrm{C}$, leading to apoptosis [34]. During the early stages of infection, Cryptosporidium inhibits host cell apoptosis by promoting the expression of the anti-apoptotic protein $\mathrm{Bcl}-2$ but decreasing the expression of the pro-apoptotic protein Bax and reducing the release of apoptosis-related mitochondrial proteins. Conversely, during the late stages of infection, the development of polypide can inhibit Bcl-2 expression and increase Bax expression, which promotes MPTP opening and further induces cell apoptosis [35]. The results of the present study demonstrated that $E$. tenella promotes MPTP opening and further increases the cell apoptosis rate. However, V5 significantly decreases the cell apoptosis rate and inhibits MPTP opening, showing that Bax is a key regulator of apoptosis in E. tenella host cells. These results are consistent with those reported for other pathogens [35].

\section{Conclusions}

In conclusion, ATP and Bax inhibitors inhibited the MPTP opening and decreased the rate of early apoptosis, late apoptosis, and necrosis of E. tenella host cells. This finding shows that ATP and Bax play important roles in regulating the apoptosis of $E$. tenella host cells.

\section{Additional files}

Additional file 1: E. tenella infection rates. ${ }^{+} p<0.05 \mathrm{vs} . \mathrm{TO}^{++}{ }^{++} p<0.01 \mathrm{vs}$. T0; ${ }^{\#}<0.05$ vs. T0, ${ }^{\# \#}<0.01$ vs. T0, as indicated below the figures. (DOCX $14 \mathrm{~kb}$ )

Additional file 2: The influence of ATP and Bax on MPTP opening of $E$. tenella host cells by flow cytometry. ${ }^{*} \mathrm{P}<0.05$ vs. $C^{* * *} \mathrm{P}<0.01$ vs. $\mathrm{C}$, the same as below figures. (DOCX $14 \mathrm{~kb}$ )

Additional file 3: The influence of ATP and Bax on the rate of early apoptosis of E. tenella host cells by flow cytometry. (DOCX $14 \mathrm{~kb}$ )

Additional file 4: The influence of ATP and Bax on the late apoptosis, and necrosis of E. tenella host cells by flow cytometry. (DOCX 14 kb)

Additional file 5: The influence of ATP and Bax on the rate of early apoptosis of E. tenella host cells by Hoechst-Annexin V/PI-based apoptosis detection. (DOCX $14 \mathrm{~kb})$

Additional file 6: The influence of ATP and Bax on the late apoptosis, and necrosis of E. tenella host cells by Hoechst-Annexin V/PI-based apoptosis detection. (DOCX $14 \mathrm{~kb}$ )

\section{Abbreviations}

Annexin V-FITC: Fluorescein isothiocyanate-conjugated Annexin V; ANT: Adenine nucleotide transporter; ATP: Adenosine triphosphate; BW: Body weight; CsA: Cyclosporin A; E. tenella: Eimeria tenella; FC: Flow cytometry; HE: Haematoxylin and eosin Stain; MPTP: Mitochondrial permeability transition pore; PI: Propidium iodide; SPF: Specific pathogen-free; V5: HVPMLK-OH, Bax-Inhibiting Peptide; VDAC: Voltage-dependent anion channel

\section{Acknowledgements}

Not applicable

\section{Funding}

This study has been funded by a grant from the National Natural Science Foundation of China (Grant No. 31272536) and the Graduate Student Innovation Fund of Shanxi Province (Grant No. 2016BY069).

\section{Availability of data and materials}

The data set(s) supporting the results of this article are included within the article.

The datasets used and/or analysed during the current study are available from the corresponding author on reasonable request.

\section{Authors' contributions}

$X Z Y$ performed most of the experiments and drafted the manuscript, and should be considered as first author. ZMX critically revised the manuscript and conceived the experimental design. ZL, ZXS, ZY, CXZ, GX, XR, and BR assisted with the experiments. All authors have read and approved the final version of the manuscript.

\section{Ethics approval and consent to participate}

Principles of laboratory animal care were followed, and all procedures were conducted according to the guidelines of the Council for the International Organizations of Medical Sciences and the International Council for Laboratory Animal Science. Every effort was made to minimise suffering. The present study was approved by the Animal Experiment Committee of Shanxi Agricultural University.

Consent for publication

Not applicable. 


\section{Competing interests}

The authors declare that they have no competing interests.

\section{Publisher's Note}

Springer Nature remains neutral with regard to jurisdictional claims in published maps and institutional affiliations.

\section{Author details}

${ }^{1}$ College of Animal Science and Technology, Shanxi Agricultural University, Taigu 030801, China. ${ }^{2}$ College of Animal Science and Technology, Henan Institute of Science and Technology, Xinxiang 453003, China.

\section{Received: 1 September 2016 Accepted: 6 December 2017}

Published online: 28 December 2017

\section{References}

1. Bachaya HA, Raza MA, Khan MN, labal Z, Abbas RZ, Murtaza S, Badar N. Predominance and detection of different Eimeria species causing coccidiosis in layer chickens. J Anim Plant Sci. 2012;22(3):597-600.

2. Dantán-González E, Quiroz-Castañeda RE, Cobaxin-Cárdenas M, ValleHernández J, Gama-Martínez Y, Tinoco-Valencia JR, Serrano-Carreón L, OrtizHernández L. Impact of Meyerozyma guilliermondii isolated from chickens against Eimeria sp. protozoan, an in vitro analysis. BMC Vet Res. 2015; doi:10.1186/s12917-015-0589-0.

3. Abdelrahman W, Mohnl M, Teichmann K, Doupovec B, Schatzmayr G, Lumpkins B, Mathis G. Comparative evaluation of probiotic and salinomycin effects on performance and coccidiosis control in broiler chickens. Poult Sci. 2014;93(12):3002-8.

4. Jatau ID, Lawal IA, Kwaga JK, Tomley FM, Blake DP, Nok AJ. Three operational taxonomic units of Eimeria are common in Nigerian chickens and may undermine effective molecular diagnosis of coccidiosis. BMC Vet Res. 2016; doi:10.1186/s12917-016-0713-9

5. Major P, Tóth Š, Goldová M, Revajová V, Kožárová I, Levkut M, Mojžišová J, Hisira V, Mihok T. Dynamic of apoptosis of cells in duodenal villi infected with Eimeria acervulina in broiler chickens. Biologia. 2011;66(4):696-700.

6. Yan Z, Zheng MX, Xu ZY, Xu HC, Cui XZ, Yang SS, Zhao WL, Li S, LV QH, Bai R. Relationship between Eimeria tenella development and host cell apoptosis in chickens. Poult Sci. 2015;94(12):2970-9.

7. Yang SS, Zheng MX, Xu HC, Cui XZ, Zhang Y, Zhao WL, Bai R. The effect of mitochondrial ATP-sensitive potassium channels on apoptosis of chick embryo cecal cells by Eimeria tenella. Res Vet Sci. 2015;99:188-95.

8. Cui XZ, Zheng MX, Zhang Y, Liu RL, Yang SS, Li S, Xu ZY, Bai R, Lv QH, Zhao WL. Calcium homeostasis in mitochondrion-mediated apoptosis of chick embryo cecal epithelial cells induced by Eimeria tenella infection. Res Vet Sci. 2016;104:166-73

9. Gu SP, Zheng MX, Li BJ. Analysis on apoptosis of chicken Cecal epithelia cells infected by E. tenella. Acta Veterinaria et Zootechnica Sinica. 2010;41(11):1322-7.

10. Xu ZY, Zheng MX, Zhang Y, Cui XZ, Yang SS, Liu RL, Li S, Lv QH, Zhao WL, Bai $R$. The effect of the mitochondrial permeability transition pore on apoptosis in Eimeria tenella host cells. Poult Sci. 2016;95(10):2405-13.

11. Devalaraja-Narashimha K, Diener AM, Padanilam BJ. Cyclophilin D gene ablation protects mice from ischemic renal injury. Am J Physiol. 2009;297(3):749-59.

12. Kubli DA, Gustafsson ÅB. Mitochondria and mitophagy: the yin and yang of cell death control. Circ Res. 2012;111(9):1208-21.

13. Li CY, Liu JZ. Structure and function of ANT and its relation to disease. J Int Pathol Clin Med. 2006;26(2):173-6.

14. Cui YM, Cheng HX, Zeng XM, Zeng QT, Gao W, Duan ML, Xu JG. Effects of hydrogen-rich saline on hippocampus mitochondrial permeability transition pore and apoptosis of rats with global cerebral ischemia-reperfusion injury. Chin Pharmocol Bull. 2012;28:853-8.

15. Adams JM, Cory S. Bcl-2-regulated apoptosis: mechanism and therapeutic potential. Curr Opin Immunol. 2007:19(5):488-96.

16. Pastorino JG, Shulga N, Hoek JB. Mitochondrial binding of hexokinase II inhibits Bax-induced cytochrome c release and apoptosis. J Biol Chem. 2002;277(9):7610-8.

17. Halestrap AP, Pasdois P. The role of the mitochondrial permeability transition pore in heart disease. Biochim Biophys Acta. 2009;1787:1402-15.
18. Ehrenreich H, Timner W, Sirén AL. A novel role for an established player: anemia drug erythropoietin for the treatment of cerebral hypoxia/ischemia. Transfus Apher Sci. 2004;31(1):39-44.

19. Bienvenu AL, Gonzalez-Rey E, Picot S. Apoptosis induced by parasitic diseases. Parasit Vectors. 2010;3 doi:10.1186/1756-3305-3-106.

20. Xu ZY, Zheng MX, Zhang Y, Cui XZ, Yang SS, Liu RL, Li S, Xi R, Gong X, Bai R. Dynamic changes in the main regulatory genes of mitochondrial permeability transition pore in Eimeria tenella host cells. Exp Parasitol. 2016; 171(10):42-8.

21. Raveche E, Abbasi F, Yuan Y, Salerno E, Kasar S, Marti GE. Introduction to flow cytometry. In: Litwin V, Marder P, editors. Flow Cytometry in drug discovery and development. New Jersey: Wiley; 2010. p. 93-9.

22. Mironov SL, Ivannikov MV, Johansson M. $\left[\mathrm{Ca}^{2+}\right]$ signaling between mitochondria and endoplasmic reticulum in neurons is regulated by microtubules. From mitochondrial permeability transition pore to $\mathrm{Ca}^{2}$ ${ }^{+}$-induced $\mathrm{Ca}^{2+}$ release. J Biol Chem. 2005;280(1):715-21.

23. Venkatanarayan A, Raulji P, Norton W, Chakravarti D, Coarfa C, Su X, Sandur SK, Ramirez MS, Lee J, Kingsley CV, Sananikone EF, Rajapakshe K, Naff K, Parker-Thornburg J, Bankson JA, Tsai KY, Gunaratne PH, Flores ER. IAPP driven metabolic reprogramming induces regression of p53-deficient tumours in vivo. Nature. 2015;517:626-30.

24. Deng JJ, Wang LX, An J. Eimeria Tenella sporozoite inhibits apoptosis in infected host cells. J Beijing Agricult Coll. 2011;26(2):24-7.

25. Jin J, Zhang F, Yang LL. Study progress of mitochondrial Uncoupler. Chin Bull Life Sci. 2013;25:707-15.

26. Doerner A, Pauschinger M, Badorff A, Noutsias M, Giessen S, Schulze K, Bilger J, Rauch U, Schultheiss HP. Tissue-specific transcription pattern of the adenine nucleotide translocase isoforms in humans. FEBS Lett. 1997:414(2):258-62.

27. Guo JY, Li Y, Pan JQ, Tang ZX. The relation of mitochondrial permeability transition pore and cell apoptosis. Prog Vet Med. 2009;30:101-5.

28. Kowaltowski AJ, Smaili SS, Russell JT. Elevation of resting mitochondrial membrane potential of neural cells by cyclosporin a, BAPTA-AM, and BCl-2. Am J Physiol Cell Physiol. 2000;279(3):C852-9.

29. Michael RD. Mitochondria in health and disease: perspectives on a new mitochondrial biology. Mol Asp Med. 2004:25(4):365-451.

30. del Cacho E, Gallego M, López-Bernad F, Quílez J, Sánchez-Acedo C. Expression of anti-apoptotic factors in cells parasitized by second-generation schizonts of Eimeria tenella and Eimeria necatrix. Vet Parasitol. 2004;125(3-4):287-300.

31. Borkan SC. The role of BCL-2 family members in acute kidney injury. Semin Nephrol. 2016;36(3):237-50.

32. Cook SA, Sugden $\mathrm{PH}$, Clerk $\mathrm{A}$. Regulation of $\mathrm{BCl}-2$ family proteins during development and in response to oxidative stress in cardiac myocytes: association with changes in mitochondrial membrane potential. Circ Res. 1999:85:940-9.

33. Brenner C, Cadiou H, Vieira HL, Zamzami N, Marzo I, Xie Z, Leber B, Andrews D, Duclohier H, Reed JC, Kroemer G. Bcl-2 and Bax regulate the channel activity of the mitochondrial adenine nucleotide translocator. Oncogene. 2000;19(3):329-36

34. Green DR. Apoptotic pathways: paper wraps stone blunts scissors. Cell. 2000;102(1):1-4.

35. Liu J, Deng M, Lancto CA. Biphasic modulation of apoptotic pathways in Cryptosporidium parvum-infected human intestinal epithelial cells. Infect Immun. 2009:77(2):837-49.

\section{Submit your next manuscript to BioMed Central and we will help you at every step:}

- We accept pre-submission inquiries

- Our selector tool helps you to find the most relevant journal

- We provide round the clock customer support

- Convenient online submission

- Thorough peer review

- Inclusion in PubMed and all major indexing services

- Maximum visibility for your research

Submit your manuscript at www.biomedcentral.com/submit 